\title{
Formation of haloacetic acids, halonitromethanes, bromate and iodate during chlorination and ozonation of seawater and saltwater of marine aquaria systems
}

\author{
Honglan Shi ${ }^{\text {a }}$, Zhimin Qiang ${ }^{\mathrm{b}}$, Craig Adams ${ }^{\mathrm{c}, *}$ \\ ${ }^{a}$ Department of Chemistry and Environmental Research Center, Missouri University of Science and Technology, Rolla, MO 65409, USA \\ ${ }^{\mathrm{b}}$ Research Center for Eco-Environmental Sciences, Chinese Academy of Sciences, Beijing 100085, China \\ ${ }^{\mathrm{c}}$ Department of Civil and Environmental Engineering, Utah State University, Logan, UT 84322, USA
}

\section{H I G H L I G H T S}

- Created methods for haloacetic acids and halonitromethanes in seawater and saltwater.

- Determined HAAs and HNMs in full scale aquaria with widely varying bromide concentrations.

- Determined effect of chlorine and ozone on HAA, HNM, bromated and iodate formation.

- Provided key information on controlling DBPs in seawater and saltwater aquaria.

\section{A R T I C L E I N F O}

\section{Article history:}

Received 23 May 2012

Received in revised form 8 September 2012

Accepted 20 September 2012

Available online 22 November 2012

\section{Keywords:}

Water disinfection

Disinfection byproducts

Aquaria

Halonitromethane

Trihalomethane

Haloacetic acid

\begin{abstract}
A B S T R A C T
This manuscript addresses identification, analysis, formation and occurrence of key disinfection byproducts (DBPs) formed during chlorination and/or ozonation of both natural seawater (NSW), and synthetic high- and low-bromide saltwater (HBSW and LBSW, respectively). In this study, several groups of water disinfection byproducts were studied, including haloacetic acids (HAAs), halonitromethanes (HNMs), bromate and iodate. Three different water systems were studied including filtered natural seawater (NSW, ca. $64.9 \mathrm{mg} \mathrm{L}^{-1} \mathrm{Br}^{-}$), a high-bromide $\left(\mathrm{Br}^{-}\right.$) saltwater (HBSW, ca. $24.8 \mathrm{mg} \mathrm{L}^{-1} \mathrm{Br}$ ), and low- $\mathrm{Br}^{-} \mathrm{salt}^{-}$ water (LBSW, ca. $4.3 \mathrm{mg} \mathrm{L}^{-1} \mathrm{Br}$ ). Because ozone reacts with $\mathrm{Cl}^{-}$to form free chlorine in seawater and salt water systems, similar DBP patterns were observed for both chlorine and ozone oxidants. The results revealed that some HAAs and HNMs are formed at greater than $100 \mu \mathrm{g} \mathrm{L}^{-1}$ concentrations and are greatly affected by water constituents and formulations when treated with chlorine and ozone. The results showed that in low- $\mathrm{Br}^{-}$water salt water, chlorinated HAAs and HNMs predominated, while much greater concentrations of brominated HAAs and HNMs were produced in both natural and synthetic higher $\mathrm{Br}^{-}$ saltwater. Concentrations of bromate and iodate were strongly impacted by factors other than $\mathrm{Br}^{-}$and $\mathrm{I}^{-}$ concentrations including whether the system was open or closed.
\end{abstract}

(c) 2012 Elsevier Ltd. All rights reserved.

\section{Introduction}

Free chlorine $\left(\mathrm{HOCl} / \mathrm{OCl}^{-}\right)$and ozone $\left(\mathrm{O}_{3}\right)$ are common disinfectants used in aquaria treatment systems. In addition to serving as an effective disinfectant, ozone is particularly valuable for its ability to enhance water clarity through both microflocculation and decolorization mechanisms. Chlorine and ozone form disinfection byproducts (DBPs) through both direct reactions, and indirect reactions with secondary oxidants formed in situ via reactions with ammonia, chloride $\left(\mathrm{Cl}^{-}\right)$, bromide $\left(\mathrm{Br}^{-}\right)$, dissolved organic matter

\footnotetext{
* Corresponding author. Tel.: +1 435797 9115; fax: +1 4357971185.

E-mail addresses: Honglan@mst.edu (H. Shi), qiangz@rcees.ac.cn (Z. Qiang), craig.adams@usu.edu (C. Adams).
}

(DOM), and other water constituents (Beech et al., 1980; Richardson et al., 1999; Reed and Adams, 2003; Zwiener et al., 2007).

The chemistry associated with chlorination and ozonation of natural seawater and saltwater (artificial sea water formulations) in aquaria is complex due to high concentrations of inorganic ions (e.g., $\mathrm{Cl}^{-}, \mathrm{Br}^{-}$, etc.) and organic compounds. Modeling work by Reed and Adams (2003) showed that the $\mathrm{Br}^{-}$concentration plays an important role in the chemical speciation within the aquaria with higher bromide concentrations leading to significant free bromine $\left(\mathrm{HOBr} / \mathrm{OBr}^{-}\right)$concentrations. Due to highly varied concentration differences of $\mathrm{Br}^{-}$(and ratios to $\mathrm{Cl}^{-}$) and DOM in the three aquaria waters, it was hypothesized that different distributions of DBPs may form at the three treated waters.

Swimming pool literature suggests that chloramines are primary disinfection byproducts (Eichelsdörfer and Slovak 1975). 
Chloramines are readily formed in situ by the reaction of free chlorine with ammonia/ammonium $\left(\mathrm{NH}_{3} / \mathrm{NH}_{4}^{+}\right)$:

$\mathrm{HOCl} / \mathrm{OCl}^{-}+\mathrm{NH}_{3} / \mathrm{NH}_{4}^{+} \rightarrow \mathrm{NClH}_{2}$

$\mathrm{HOCl} / \mathrm{OCl}^{-}+\mathrm{NClH}_{2} \rightarrow \mathrm{NCl}_{2} \mathrm{H}$

$\mathrm{HOCl} / \mathrm{OCl}^{-}+\mathrm{NCl}_{2} \mathrm{H} \rightarrow \mathrm{NCl}_{3}$

Ammonia is present from excrement and other sources especially in natural seawater. During water treatment, free chlorine may be added directly to the water, or may be formed in situ by the reaction of ozone with the high concentrations of $\mathrm{Cl}^{-}$present in natural seawater and artificial saltwater formulations. Free bromine $(\mathrm{HOBr} /$ $\mathrm{OBr}^{-}$) is also readily formed by the reaction of free chlorine with the $\mathrm{Br}^{-}$. In reactions analogous to those shown above, bromamines are formed by the reactions of free bromine and ammonia/ammonium. Thus, during either chlorination or ozonation of seawater or saltwater, a suite of chloramines and bromamines may be formed in varied concentrations depending on the specific makeup of the water. It is likely that iodide $\left(\mathrm{I}^{-}\right)$present in seawater/saltwater formations also plays an important role in DBP formation in an analogous manner to the $\mathrm{Cl}^{-}$and $\mathrm{Br}^{-}$.

Trihalomethanes (THMs) and five haloacetic acids (HAAs) are regulated DBPs in drinking water for chloro- and bromo-species, while iodo-THMs and other HAAs are not currently regulated. The sum of the four chloro- and bromo-THMs are regulated at a limit of $80 \mu \mathrm{g} \mathrm{L}^{-1}$ in drinking water (USEPA, 2006). Previous work by Shi and Adams (2012) observed concentrations of THMs in seawater/saltwater aquaria at concentrations ranging up to $140 \mu \mathrm{g} \mathrm{L}^{-1}$.

Haloacetic acids are known disinfection byproducts in drinking and swimming pool waters (Zwiener et al., 2007). The sum of five of the chloro- and bromo-HAAs (monochloroacetic acid (MCAA), dichloroacetic acid (DCAA), trichloroacetic acid (TCAA), monobromoacetic acid (MBAA), and dibromoactic acid (DBAA)) are regulated at a limit of $60 \mu \mathrm{g} \mathrm{L}^{-1}$ in drinking water (USEPA, 2006). Shi and Adams (2009) observed concentrations of monobromoacetic acid (MBAA) of $192 \mu \mathrm{g} \mathrm{L}^{-1}$ while monitoring for a wide suite of chloro-, bromo- and iodo-acetic acids.

Iodo-DBPs (including iodo-THMs and HAAs) may also be significant disinfection byproducts, though they have not been fre- quently measured due to lack of reliable analytical methods. Bromate is formed as a terminal oxidation byproduct for bromine in aqueous systems. While bromate in drinking water is analyzed using ion chromatography (IC) methods (USEPA Methods 300.1 and 326), high $\mathrm{Cl}^{-}$concentrations in seawater and saltwater makes these methods unusable for marine aquaria. A new method was developed by Shi and Adams (2009) to analyze bromate concentrations in seawater/saltwater using ICPMS, and which was used in this study. While halonitromethanes (HNMs) are a group of toxic emerging DBPs in drinking water, no studies have been conducted on HNM formation in seawater and saltwater systems.

The purpose of this study was to evaluate the occurrence and formation of a suite of inorganic halogen species, HAAs and HNMs in seawater/saltwater aquaria systems disinfected with chlorine and ozone. In this study, water samples included both field samples from aquaria and laboratory prepared samples from disinfection experiments using chlorine and ozone.

\section{Methods}

\subsection{Chemicals and instruments}

Iodoacetic acids including chloroiodoacetic acid (CIAA), bromoiodoacetic acid (BIAA), diiodoacetic acid (DIAA), halonitromethane (HNM) standards including chloronitromethane (CNM), dichloronitromethane (DCNM), dibromonitromethane (DBNM), tribromonitromethane (TBNM), bromochloronitromethane (BCNM), bromodichloronitromethane (BDCNM), and dibromochloronitromethane (DBCNM), were purchased from Orchid Cellmark (New Westminster, BC, Canada). The other DBP standards monoiodoacetic acid (MIAA), monobromoacetic acid (MBAA), bromochloroacetic acid (BCAA), dibromoacetic acid (DBAA), bromodichloroacetc acid (BDCAA), dibromochloroacetic acid (DBCAA), tribromoacetic acid (TBAA), bromonitromethane (BNM), and trichloronitromethane (TCNM), were purchased from Sigma-Aldrich (St. Louis, MO, USA). Naphthalene- $\mathrm{d}_{8}$, sodium hypochlorite, sodium bromide, and sodium iodide were also products of Sigma-Aldrich. All of these chemicals were of the highest purity available. Deionized (DI) water $(18.2 \mathrm{M} \Omega \mathrm{cm}$ ) was prepared by using a Milli-Q water purification system (Millipore, Bedford, MA, USA). Methanol, so-

Table 1

Formations of HAAs and other halogenated compounds by chlorination and ozonation of marine aquaria water samples.

\begin{tabular}{|c|c|c|c|c|c|c|c|c|c|c|c|c|c|}
\hline \multirow[t]{2}{*}{ Sample ID } & \multirow[t]{2}{*}{ Treatment } & \multicolumn{7}{|c|}{ Bromoacetic acid concentrations (MSA) } & \multirow{2}{*}{$\begin{array}{l}\mathrm{BrO}_{3}^{-} \\
\left(\mathrm{mg} \mathrm{L}^{-1}\right)\end{array}$} & \multirow{3}{*}{$\begin{array}{l}\mathrm{Br}^{-} \\
\left(\mathrm{mg} \mathrm{L}^{-1}\right)\end{array}$} & \multirow{3}{*}{$\begin{array}{l}\mathrm{IO}_{3} \\
\left(\mathrm{mg} \mathrm{L}^{-1}\right)\end{array}$} & \multirow{3}{*}{$\begin{array}{l}\mathrm{BrO}_{3}^{-} / \mathrm{Br}^{-} \\
\text {Molar ratio }\end{array}$} & \multirow{2}{*}{$\begin{array}{l}\mathrm{BrO}_{3}^{-} / \mathrm{IO}_{3}^{-} \\
\text {Molar ratio }\end{array}$} \\
\hline & & MBAA & BCAA & DBAA & BDCAA & DBCAA & TBAA & BAAs & & & & & \\
\hline \multicolumn{11}{|l|}{ NSW } & & & \\
\hline Inlet & No treatment & $<2.54$ & $<2.63$ & $<1.36$ & $<3.28$ & $<2.15$ & 54 & 54 & $<0.00165$ & 64.0 & 0.090 & $<0.00002$ & $<0.025$ \\
\hline Inlet & Free chlorine & $<2.54$ & $<2.63$ & $<1.36$ & $<3.28$ & $<2.15$ & 55 & 55 & $<0.00165$ & No data & No data & No data & No data \\
\hline Inlet & Ozone & $<2.54$ & $<2.63$ & $<1.36$ & $<3.28$ & $<2.15$ & 61 & 61 & $<0.00165$ & 58.6 & 0.176 & $<0.00002$ & $<0.013$ \\
\hline Main basin & No treatment & $<2.54$ & $<2.63$ & $<1.36$ & $<3.28$ & $<2.15$ & 19 & 19 & $<0.00165$ & 62.4 & 0.081 & $<0.00002$ & $<0.028$ \\
\hline Main basin & Free chlorine & $<2.54$ & $<2.63$ & $<1.36$ & $<3.28$ & $<2.15$ & 44 & 44 & $<0.00165$ & 55.7 & 0.171 & $<0.00002$ & $<0.013$ \\
\hline Main basin & Ozone & $<2.54$ & $<2.63$ & $<1.36$ & $<3.28$ & $<2.15$ & 38 & 38 & $<0.00165$ & 61.2 & 0.179 & $<0.00002$ & $<0.013$ \\
\hline \multicolumn{14}{|l|}{ HBSW } \\
\hline Inlet & No treatment & $<2.54$ & 90 & $<1.36$ & 28 & $<2.15$ & 69 & 187 & No data & 21.5 & 0.032 & No data & No data \\
\hline Inlet & Free chlorine & $<2.54$ & $<2.63$ & 59 & 40 & 17 & 91 & 207 & 1.10 & 19.5 & 0.135 & 0.04 & 11 \\
\hline Inlet & Ozone & $<2.54$ & $<2.63$ & 50 & 46 & 13 & 85 & 194 & 0.90 & 26.9 & 0.117 & 0.02 & 11 \\
\hline Main basin & No treatment & $<2.54$ & 55 & $<1.36$ & 27 & 7 & 116 & 205 & No data & 21.6 & 0.034 & No data & No data \\
\hline Main basin & Free chlorine & $<2.54$ & $<2.63$ & 62 & 53 & 16 & 134 & 265 & 0.81 & 18.5 & 0.121 & 0.03 & 9 \\
\hline Main basin & Ozone & $<2.54$ & $<2.63$ & 56 & 62 & 17 & 150 & 285 & 0.75 & 26.6 & 0.106 & 0.02 & 10 \\
\hline \multicolumn{14}{|l|}{ LBSW } \\
\hline Inlet & No treatment & $<2.54$ & $<2.63$ & $<1.36$ & 122 & 36 & $<2.01$ & 158 & 3.79 & 1.54 & 0.034 & 1.54 & 155 \\
\hline Inlet & Free chlorine & $<2.54$ & $<2.63$ & 9 & 119 & 37 & $<2.01$ & 165 & 4.39 & 1.90 & 0.184 & 1.44 & 33 \\
\hline Inlet & Ozone & $<2.54$ & $<2.63$ & 28 & 139 & 47 & $<2.01$ & 214 & 3.86 & 1.62 & 0.120 & 1.49 & 44 \\
\hline Main basin & No treatment & $<2.54$ & $<2.63$ & $<1.36$ & 189 & 34 & $<2.01$ & 223 & 3.68 & 1.48 & 0.034 & 1.55 & 148 \\
\hline Main basin & Free chlorine & $<2.54$ & $<2.63$ & 16 & 108 & 35 & $<2.01$ & 159 & 3.65 & 1.37 & 0.173 & 1.66 & 29 \\
\hline Main basin & Ozone & $<2.54$ & $<2.63$ & 9 & 135 & 40 & $<2.01$ & 184 & 3.63 & 1.71 & 0.145 & 1.33 & 34 \\
\hline
\end{tabular}


dium sulfate, ascorbic acid, ammonium hydroxide, copper sulfate, and methyl-tert-butyl ether (MTBE) were purchased from Fisher Scientific (Pittsburgh, PA, USA). Diethyl-p-phenylenediamine (DPD) test kits were purchased from HACH Company (Loveland, CO, USA). Ozone used for ozonation test was produced on site with an ozone generator (Model GLS-1, PCI-WEDECO Environmental Technologies, West Caldwell, NJ, USA).

\subsection{Water sample collection}

Water samples were collected from seawater and saltwater treatment aquaria systems with pre-cleaned amber glass bottles shipped from our laboratory. These systems each involve a large basin (or basins) from which water is taken, treated, and returned to the basin through inlets. For the LBSW system, water was never

Table 2

HAAs concentrations in seawater and saltwater samples from marine aquaria.

\begin{tabular}{|c|c|c|c|c|c|c|c|c|c|c|}
\hline \multirow[t]{2}{*}{ Aquaria } & \multicolumn{10}{|c|}{ HAA concentration $\left(\mu \mathrm{g} \mathrm{L}^{-1}\right)$} \\
\hline & MCAA & DCAA & TCAA & MBAA & BCAA & DBAA & BDGAA & DBCAA & TBAA & HAAs \\
\hline NSW & $<\mathrm{MDL}$ & $<\mathrm{MDL}$ & 3.1 & $<\mathrm{MDL}$ & $<\mathrm{MDL}$ & 16.7 & 13.3 & 12.0 & 43.3 & 88.4 \\
\hline HBSW & 16.0 & $<\mathrm{MDL}$ & 7.5 & $<\mathrm{MDL}$ & 13.8 & 46.7 & 12.0 & 14.2 & 52.2 & 162 \\
\hline LBSW & 3.0 & 6.10 & 193 & $<\mathrm{MDL}$ & 7.7 & 15.0 & 47.3 & 42.7 & 35.6 & 350 \\
\hline
\end{tabular}

Table 3

Formation of HNMs by chlorination of marine aquaria water for $15 \mathrm{~min}$.

\begin{tabular}{|c|c|c|c|c|c|c|c|c|}
\hline \multirow[t]{2}{*}{ Sample } & \multirow[t]{2}{*}{ FC treatment } & \multicolumn{7}{|c|}{ HNMs concentration $\left(\mathrm{ng} \mathrm{L}^{-1}\right)$} \\
\hline & & CNM & DCNM & TCNM & BNM & BCNM & DBNM & Total HNM \\
\hline \multicolumn{9}{|l|}{ NSW } \\
\hline Inlet & No treatment & 4.0 & $<0.09$ & $<0.10$ & 0.8 & 0.3 & 1.0 & 6.1 \\
\hline Inlet & $1 \mathrm{mg} \mathrm{L}^{-1}$ & 1.2 & 0.5 & 1.2 & 0.4 & 1.8 & 11.3 & 16.5 \\
\hline Inlet & $3 \mathrm{mg} \mathrm{L}^{-1}$ & 1.1 & $<0.09$ & 2.3 & 2.1 & 2.0 & 7.1 & 14.6 \\
\hline Main basin & No treatment & 0.5 & $<0.09$ & 0.5 & 0.2 & 0.2 & 1.0 & 2.5 \\
\hline Main basin & $1 \mathrm{mg} \mathrm{L}^{-1}$ & 1.2 & $<0.09$ & 0.5 & 1.5 & 1.0 & 1.3 & 5.5 \\
\hline Main basin & $3 \mathrm{mg} \mathrm{L}^{-1}$ & 1.0 & $<0.09$ & 4.5 & 0.8 & 1.7 & 4.9 & 12.9 \\
\hline \multicolumn{9}{|l|}{ HBSW } \\
\hline Inlet & No treatment & 1.0 & 0.5 & $<0.10$ & 0.4 & 0.3 & 3.5 & 5.6 \\
\hline Inlet & $1 \mathrm{mg} \mathrm{L}^{-1}$ & 1.2 & $<0.09$ & 1.0 & 0.2 & 3.6 & 10.7 & 16.8 \\
\hline Inlet & $3 \mathrm{mg} \mathrm{L}^{-1}$ & 1.4 & $<0.09$ & 2.6 & 1.0 & 2.8 & 7.2 & 15.0 \\
\hline Main basin & No treatment & 0.8 & $<0.09$ & $<0.10$ & 0.6 & 0.6 & 3.2 & 5.1 \\
\hline Main basin & $1 \mathrm{mg} \mathrm{L}^{-1}$ & 1.0 & $<0.09$ & 0.1 & 0.1 & 3.5 & 9.5 & 14.2 \\
\hline Main basin & $3 \mathrm{mg} \mathrm{L}^{-1}$ & 1.4 & $<0.09$ & 2.8 & 0.8 & 2.6 & 8.0 & 15.6 \\
\hline \multicolumn{9}{|l|}{ LBSW } \\
\hline Inlet & No treatment & 0.0 & 2.1 & 36.2 & 2.3 & 2.7 & 5.2 & 48.5 \\
\hline Inlet & $1 \mathrm{mg} \mathrm{L}^{-1}$ & 0.5 & 5.0 & 79.9 & 0.1 & 7.9 & 18.3 & 111.7 \\
\hline Inlet & $3 \mathrm{mg} \mathrm{L}^{-1}$ & 1.6 & 2.8 & 60.3 & 1.6 & 7.0 & 14.4 & 87.7 \\
\hline Main basin & No treatment & 0.0 & 3.2 & 47.7 & 2.8 & 5.1 & 10.9 & 69.7 \\
\hline Main basin & $1 \mathrm{mg} \mathrm{L}^{-1}$ & 0.8 & 3.3 & 110.0 & 0.2 & 8.0 & 28.6 & 150.9 \\
\hline Main basin & $3 \mathrm{mg} \mathrm{L}^{-1}$ & 1.4 & 2.1 & 101.0 & 1.7 & 8.3 & 19.9 & 134.4 \\
\hline
\end{tabular}

Table 4

Formation of HNMs by ozonation of marine aquaria water for $15 \mathrm{~min}$.

\begin{tabular}{|c|c|c|c|c|c|c|c|c|}
\hline \multirow[t]{2}{*}{ Sample } & \multirow[t]{2}{*}{ OZ treatment } & \multicolumn{7}{|c|}{ HNMs concentration $\left(\mu \mathrm{g} \mathrm{L}^{-1}\right)$} \\
\hline & & CNM & DCNM & TCNM & BNM & BCNM & DBNM & Total HNM \\
\hline \multicolumn{9}{|l|}{ NSW } \\
\hline Inlet & No treatment & 4.0 & $<0.09$ & $<0.1$ & 0.8 & 0.3 & 1.0 & 6.1 \\
\hline Inlet & $1 \mathrm{mg} \mathrm{L}^{-1}$ & 3.0 & $<0.09$ & $<0.1$ & 3.0 & 2.0 & 8.5 & 16.5 \\
\hline Inlet & $3 \mathrm{mg} \mathrm{L}^{-1}$ & 2.6 & 0.4 & $<0.1$ & 2.9 & 5.9 & 23.0 & 34.8 \\
\hline Main basin & No treatment & 0.5 & $<0.09$ & 0.5 & 0.2 & 0.2 & 1.0 & 2.5 \\
\hline Main basin & $1 \mathrm{mg} \mathrm{L}^{-1}$ & 3.1 & $<0.09$ & $<0.1$ & 5.4 & 0.6 & 3.5 & 12.6 \\
\hline Main basin & $3 \mathrm{mg} \mathrm{L}^{-1}$ & 2.6 & $<0.09$ & 0.6 & 3.4 & 5.8 & 23.7 & 36.1 \\
\hline \multicolumn{9}{|l|}{ HBSW } \\
\hline Inlet & No treatment & 1.0 & 0.5 & $<0.1$ & 0.4 & 0.3 & 3.5 & 5.6 \\
\hline Inlet & $1 \mathrm{mg} \mathrm{L}^{-1}$ & 2.0 & $<0.09$ & $<0.1$ & 2.6 & 2.8 & 11.3 & 18.7 \\
\hline Inlet & $3 \mathrm{mg} \mathrm{L}^{-1}$ & 1.7 & 0.4 & 1.9 & 2.6 & 7.5 & 10.8 & 24.9 \\
\hline Main basin & No treatment & 0.8 & $<0.09$ & $<0.1$ & 0.6 & 0.6 & 3.2 & 5.1 \\
\hline Main basin & $1 \mathrm{mg} \mathrm{L}^{-1}$ & 1.7 & $<0.09$ & $<0.1$ & 2.7 & 2.9 & 13.5 & 20.8 \\
\hline Main basin & $3 \mathrm{mg} \mathrm{L}^{-1}$ & 1.5 & 0.5 & 1.9 & 2.6 & 6.9 & 16.9 & 30.3 \\
\hline \multicolumn{9}{|l|}{ LBSW } \\
\hline Inlet & No treatment & $\mathrm{ND}^{\mathrm{a}}$ & ND & ND & ND & ND & ND & ND \\
\hline Inlet & $1 \mathrm{mg} \mathrm{L}^{-1}$ & 0.0 & 0.4 & 25.9 & 2.2 & 0.7 & 1.9 & 31.1 \\
\hline Inlet & $3 \mathrm{mg} \mathrm{L}^{-1}$ & 0.8 & 0.4 & 26.5 & 2.1 & 1.1 & 4.8 & 35.7 \\
\hline Main basin & No treatment & ND & ND & ND & ND & ND & ND & ND \\
\hline Main basin & $1 \mathrm{mg} \mathrm{L}^{-1}$ & 0.5 & 0.5 & 31.3 & 2.1 & 0.8 & 2.1 & 37.3 \\
\hline Main basin & $3 \mathrm{mg} \mathrm{L}^{-1}$ & 0.4 & 0.5 & 39.7 & 2.1 & 0.9 & 4.6 & 48.2 \\
\hline
\end{tabular}

ND ${ }^{\mathrm{a}}$ - No data. 
wasted, that is, it was a closed system. For the HBSW and NSW systems, water is periodically wasted, that is, they are open systems. Treatment of the water in all cases includes filtration, and chlorination and/or ozonation.

All the samples were collected from locations with both short (e.g., $2 \mathrm{~min}$ ) at the "inlets" to the basin, and long (e.g., hours) contact times from the basins themselves. The samples were placed in cold coolers and shipped to the laboratory overnight for analysis. Water samples were collected and tested in both the colder winter months and warmer summer months. Both inlet and main basin waters were tested for winter samples, and only main basin samples were tested in summer samples.

\subsection{DBPs and related halogenated compounds analysis}

The total $\mathrm{Br}$ and total I concentrations were detected by inductively coupled plasma-mass spectrometry (ICP-MS) (Shi and Adams, 2009). Speciation analysis of bromo- and iodo-compounds (i.e., bromoacetic acids, iodoacetic acids, bromate, iodate, and their precursors $\mathrm{Br}^{-}$and $\mathrm{I}^{-}$) in the marine aquaria waters were conducted by ion chromatography (IC) coupled with ICP-MS (Shi and Adams, 2009). Due to the large concentration variation of the analytes, different dilutions were made for different compounds before analysis.

IC-ICP-MS analysis of BAAs, IAAs, bromate, and related compounds was conducted using a Perkin Elmer 200 Series HPLC and an Elan DRCe ICP-MS (Perkin Elmer, Norwalk, CT, USA). The GCMS system used for HNMs analysis was an Agilent 6890 GC with a 5973N mass selective detector (Agilent Technologies, Palo Alto, CA, USA).

HNMs were analyzed by a liquid-liquid extraction followed by gas chromatography-mass spectrometry (LLE-GC-MS) method adapted from published HNMs analytical methods (Krasner et al., 2001; Chen et al., 2002; Weinberg et al., 2002; Plewa et al., 2004). The collected aquaria water samples were extracted within $48 \mathrm{~h}$ of arriving in the laboratory by LLE extraction procedure and were analyzed by GC-MS within 1 week.

\subsection{Disinfection treatments}

Although the occurrence studies of DBPs and related compounds were conducted for the treated aquaria samples, additional laboratory experiments were also conducted to study DBP formation. The DBPs and related compounds were analyzed prior to and subsequent to oxidation. For free chlorine treatment tests of HAA formation, free chlorine was added into the water samples at a concentration of $3 \mathrm{mg} \mathrm{L}^{-1}$ and allowed to react for $30 \mathrm{~min}$ at room temperature $\left(23^{\circ} \mathrm{C}\right)$. The ozone treatments were performed by adding concentrated ozone stock solution at concentration
$3 \mathrm{mg} \mathrm{L}^{-1}$ and allowed to react for $30 \mathrm{~min}$ at room temperature $\left(23^{\circ} \mathrm{C}\right)$.

HNMs formation in seawater and saltwater was studied by treatment with chlorine and ozone at concentrations of both 1 and $3 \mathrm{mg} \mathrm{L}^{-1}$. The treatment procedure for both chlorine and ozone was: transfer $35 \mathrm{~mL}$ of water sample into a $40-\mathrm{mL}$ vial; spike a small amount of chlorine stock solution into the sample to make the chlorine or ozone concentration 1 or $3 \mathrm{mg} \mathrm{L}^{-1}$; react for 15 (and/or 60) $\mathrm{min}$ at room temperature $\left(23^{\circ} \mathrm{C}\right.$ ), and then extract with $4 \mathrm{~mL}$ MTBE. The extraction was performed immediately at the end of the treatment time so that quenching agent was not used.

\subsection{Quality control}

To ensure data quality, QA/QC procedures based on EPA methods were followed. Instrument calibration curves always exhibited correlation coefficients of 0.99 or greater. For all analyses, at least one standard solution was measured for every 10-15 samples to ensure the instrument is remained calibrated with consistent response. If any check standard deviated by $10 \%$ or greater, a calibration curve was re-run and the samples were reanalyzed. The estimated instrument detection limits were calculated at 3-5 times of signal/noise ratio. Reagent blanks were included in each batch of samples. Duplications were performed for every 10-12 samples. Sample spike recovery tests were also included, whenever appropriate, for each type of sample matrix or each batch of samples with spike recoveries in the range of $90-110 \%$ deemed acceptable.

\section{Results and discussions}

\subsection{Inorganic species}

Total $\mathrm{Br}$ concentrations in treated aquaria water samples averaged 1619, 503 and 149 times total I concentrations in NSW, HBSW, and LBSW, respectively. The sum of all $\mathrm{Br}$ species in each aquaria sample was highest in the natural seawater (NSW) and lowest in the low $\mathrm{Br}$ saltwater (LBSW) samples. Specifically, NSW, HBSW and LBSW had median (from samples collected in January, May, and August) total $\mathrm{Br}$ concentrations of $64.9,24.8$, and $4.3 \mathrm{mg} \mathrm{L}^{-1}$, respectively.

Total I species followed the same trend with the exception of the summer samples which had lower total I in the NSW than the HBSW (and LBSW) samples due potentially to natural seasonal variation in the ocean's I levels (data not shown). NSW, HBSW and LBSW had median total I concentrations of 61 (range of 51$\left.95 \mu \mathrm{g} \mathrm{L}^{-1}\right), 80$, and $48 \mu \mathrm{g} \mathrm{L}^{-1}$, respectively. HBSW and LBSW were prepared using sodium chloride (and many other constituents)

Table 5

Formation of HNMs by treatment for $60 \mathrm{~min}$ with chlorine $\left(3 \mathrm{mg} \mathrm{L}^{-1}\right)$ and ozone $\left(3 \mathrm{mg} \mathrm{L}^{-1}\right)$ in marine aquaria water collected in May, 2008.

\begin{tabular}{|c|c|c|c|c|c|c|c|}
\hline \multirow[t]{2}{*}{ Sample } & \multicolumn{7}{|c|}{ HNMs concentration $\left(\mu \mathrm{g} \mathrm{L}^{-1}\right)$} \\
\hline & CNM & DCNM & TCNM & BNM & BCNM & DBNM & Total HNM \\
\hline \multicolumn{8}{|l|}{ NSW } \\
\hline Main basin water no treatment & $<0.07$ & $<0.09$ & $<0.10$ & 5.0 & $<0.10$ & 9.0 & 14.0 \\
\hline Main basin water treated with FC & 5.4 & $<0.09$ & $<0.10$ & 4.9 & 6.4 & 8.9 & 25.6 \\
\hline Main basin water treated with 03 & 5.9 & $<0.09$ & $<0.10$ & 5.6 & 7.1 & 11.8 & 30.4 \\
\hline \multicolumn{8}{|l|}{ HBSW } \\
\hline Main basin water no treatment & $<0.07$ & $<0.09$ & $<0.10$ & $<0.06$ & 6.0 & 7.1 & 13.1 \\
\hline Main basin water treated with FC & 5.2 & $<0.09$ & $<0.10$ & $<0.06$ & 6.3 & 9.0 & 20.5 \\
\hline Main basin water treated with 03 & 6.3 & $<0.09$ & $<0.10$ & 5.5 & 7.1 & 12.1 & 30.9 \\
\hline \multicolumn{8}{|l|}{ LBSW } \\
\hline Main basin water no treatment & $<0.07$ & 10.2 & 46.6 & 4.9 & 6.6 & 6.9 & 75.2 \\
\hline Main basin water treated with FC & 4.4 & 6.5 & 51.6 & $<0.06$ & 6.8 & 7.6 & 76.9 \\
\hline Main basin water treated with 03 & 7.0 & 9.9 & 43.5 & $<0.06$ & 7.6 & 7.9 & 75.8 \\
\hline
\end{tabular}


that had widely varied $\mathrm{Br}$ concentrations as is reflected in the total $\mathrm{Br}$ and I measurements. These wide variations in $\mathrm{Br}$ concentration have the potential to greatly affect the speciation and oxidation pathways for not only $\mathrm{Br}$ species, but also $\mathrm{Cl}$ and I species due to different rates of reaction and competitive kinetics.

Bromate and iodate were measured in all three aquaria waters. The LBSW had very high bromate concentrations (median: $3700 \mu \mathrm{g} \mathrm{L}^{-1}$ ), while the NSW system had very low concentrations $\left(<2 \mu \mathrm{g} \mathrm{L}^{-1}\right)$ (Table 1 ). While $\mathrm{Br}^{-}$was still present in relatively high concentrations in the NSW and HBSW, bromate remained low.

It is hypothesized that the reason for these large differences is due to a combination of factors. The LBSW is a closed, zero-discharge system, that is, there is no discharge or wasting of water from the tanks. Therefore, bromate (the terminal oxidation byproduct) continuously builds up in the system. This is combined with typically higher ozone doses used in the LBSW aquaria, than is used in the other aquaria. While the NSW aquaria water also had high $\mathrm{Br}$, the bromate concentration is hypothesized to remain low because it is semi-open, that is, fresh seawater is added to recirculated systems at a rate that would exchange the total system volume over one to $30 \mathrm{~d}$. Iodate ranged from $32-34 \mu \mathrm{g} \mathrm{L}^{-1}$ in the HBSW and LBSW to $81-90 \mu \mathrm{g} \mathrm{L}^{-1}$ in the NSW.

\subsection{Haloacetic acids}

As shown in Table 1, bromoacetic acids (BAA) were much higher in both the HBSW (187-205 $\left.\mu \mathrm{g} \mathrm{L}^{-1}\right)$ and LBSW $\left(158-223 \mu \mathrm{g} \mathrm{L}^{-1}\right)$ than in the NSW (19-54 $\left.\mathrm{g} \mathrm{L}^{-1}\right)$ systems. It is hypothesized that this is due to the NSW system being semi-open with fresh seawater being brought in and treated seawater being discharged each day, compared with the closed (no wastage) LBSW system. Each system has a different mix of BAAs (Table 1). TBAA was the domi-
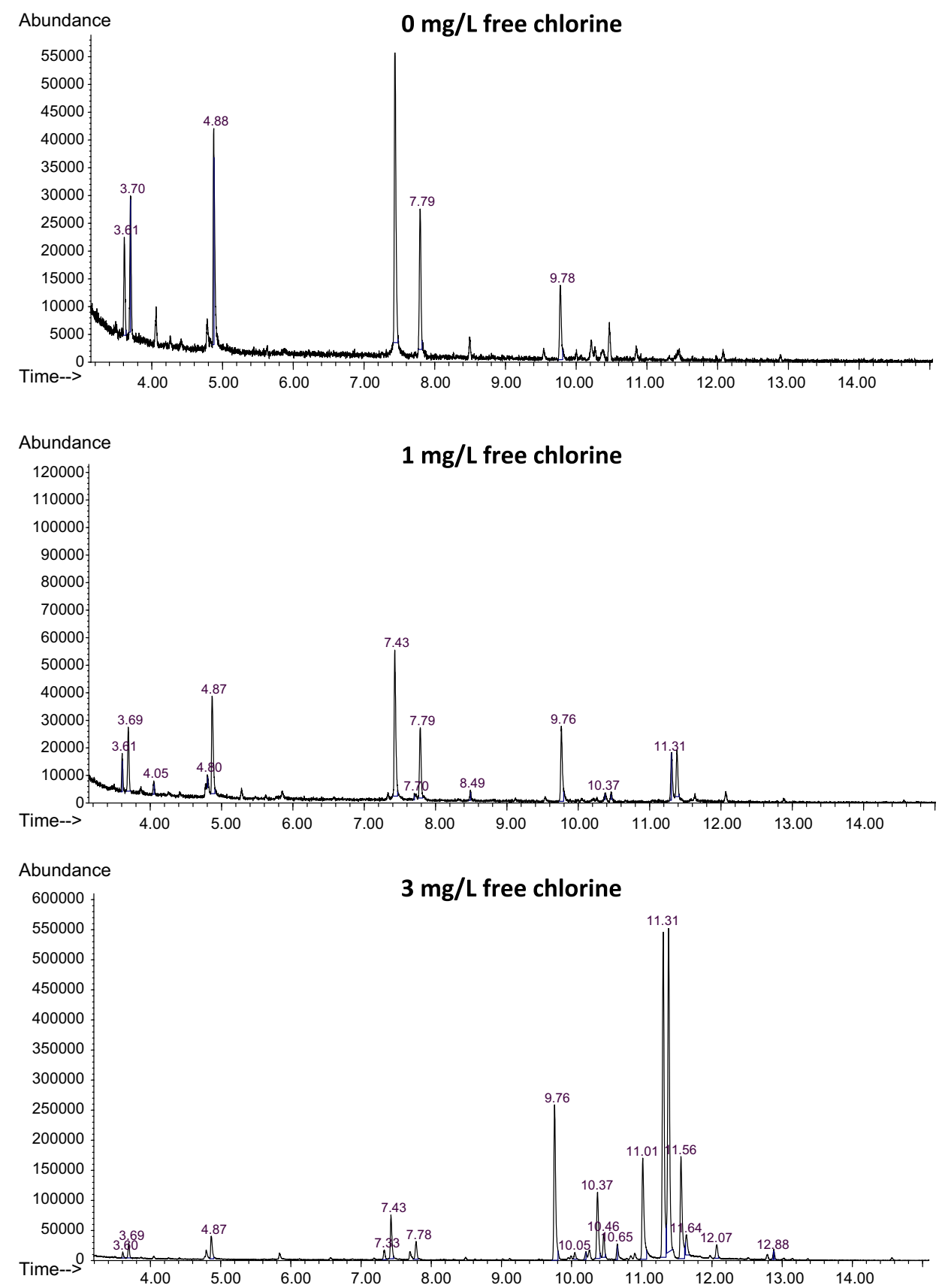

Fig. 1. Total ion chromatograms of NSW treated with $0 \mathrm{mg} \mathrm{L}^{-1}$ (top), $1 \mathrm{mg} \mathrm{L}^{-1}$ (middle), and $3 \mathrm{mg} \mathrm{L}^{-1}$ (bottom) of free chlorine. 
nant species in natural sea water NSW system without any other BAA at detectable level. TBAA was also dominant species in high$\mathrm{Br}^{-}$HBSW salt water system, followed by DBAA, BDCAA, and DBCAA. In contrast, TBAA was not at detectable level in the low-
$\mathrm{Br}^{-}$LBSW salt water system, while BDCAA was highest followed by DBCAA. CAAs were not analyzed in the experiments for Table 1 because the simultaneous detection of $\mathrm{Br}$ - and I-species by IC-ICPMS analytical method is not suitable for chlorine compound. A pre-
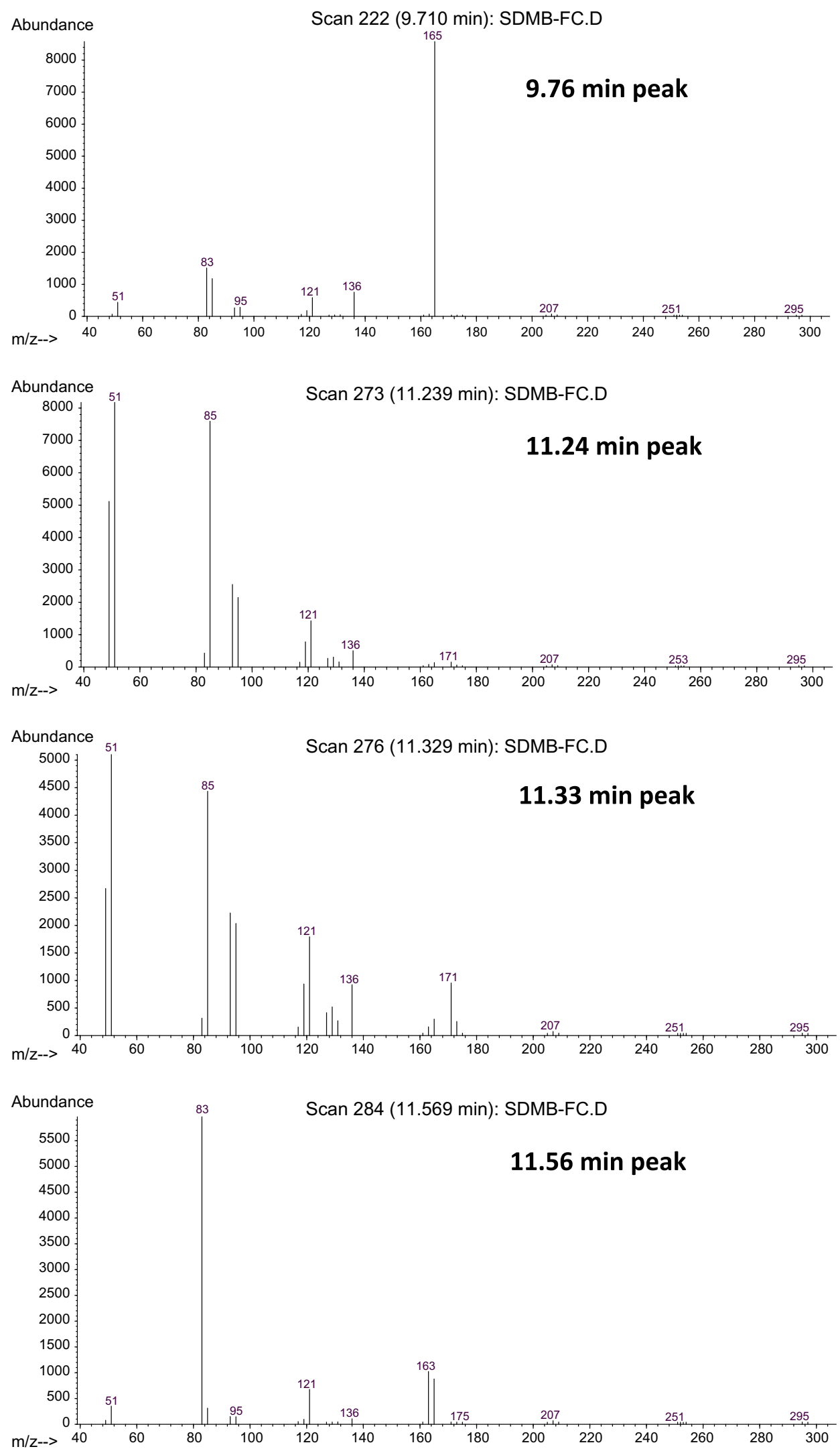

Fig. 2. Mass spectra of unknown compound peaks in chlorine-treated NSW aquaria water samples. 
vious study conducted approximately one year earlier on the same aquaria showed similar concentration trends of BAAs (Table 2). TBAA was again a dominant species in both the NSW and HBSW aquaria with very minimum CAAs. In the LBSW, however, TCAA were found at the highest concentration, with BDCAA, DBCAA, and TBAA had the next highest concentrations.

Formation of HAAs, bromate, and iodate in the three marine aquaria waters were examined in laboratory chlorination and ozonation studies. For the NSW, chlorination and ozonation at typical treatment dosages had little effect on HAA or bromate concentrations (Table 1). Formation of iodate was observed for both free chlorine and ozone. For the HBSW, increased formations of TBAA, DBCAA, BDCAA, and DBAA were all observed, while BCAA was consumed (that is, converted to another species, e.g., DBCAA and BDCAA) (Table 1). High concentrations of both bromate and iodate were also observed to concentrations of $750-1100 \mu \mathrm{g} \mathrm{L}^{-1}$ and 106$135 \mu \mathrm{g} \mathrm{L}^{-1}$, respectively. For the LBSW, only slight increases in DBCAA and DBAA were observed for the HAAs (Table 1). While bromate concentrations were high before and after chlorine and ozone treatment, a significant increase in iodate was observed with both chlorine and ozone (particularly in chlorination) (Table 1).

\subsection{Halonitromethanes}

HNMs are one group of the more recently discovered DBPs with very high toxicity (Krasner et al., 2006; Richardson et al., 2007). Calibration standards for HNMs were prepared in saltwater (containing the same major components as the seawater). Six HNMs were analyzed, while TBNM and DBCNM were not analyzed in this study because of a lack of reliable standards. The linear calibration concentration range used was $1-1000 \mu \mathrm{g} \mathrm{L}^{-1}\left(R^{2}>0.99\right)$. Water samples for HNM analysis were collected in both a cold and a warm month.

The concentrations of six detected HNMs in LBSW were higher than in NSW and HBSW waters (Tables 3 and 4). The highest concentrations were observed in the warmer (May) sample with BNM and DBNM being the dominant species. For comparison with these data, Weinberg et al. (2002) found concentrations of HNMs in drinking water in the range of $0.1-3.0 \mu \mathrm{g} \mathrm{L}^{-1}$.

Total $\mathrm{Br}$ concentrations in NSW and HBSW were much higher than those in LBSW (Table 1), leading to the formation of more brominated HNMs (Tables 3 and 4). For NSW, the dominant species in the winter months were CNM, BNM and DBNM for the inlet, and CNM, TCNM and DBNM in the main basin. For the HBSW, the dominant species was DBNM (and BCNM to a lesser degree) (Tables 3 and 4). For the LBSW, the dominant species was TCNM (and DCNM, BCNM, and DBNM to a lesser degree). Clearly, formation and occurrence of HNMs is highly dependent on differences in water constituents and treatment processes.

Laboratory chlorination and ozonation studies were conducted at typical doses and contact times. For all three aquaria waters, significant (and generally relatively similar) increases in HNMs were observed with both chlorine and ozone treatments.

For chlorination of the two waters with highest bromide (NSW and HBSW) with 15 min contact, the dominant HNM species formed was DBNM followed by BCNM and TCNM, and then CNM and BNM. For the LBSW, however, very high concentrations of the $\mathrm{Br}$-free TCNM was formed sometimes to greater than $100 \mu \mathrm{g} \mathrm{L}^{-1}$ for the main basin water (Table 3). DBNM, BCNM, $B N M$, and DCNM were also formed in significant concentrations in the LBSW.

For ozonation, of the three aquaria waters, the HNM speciation results were highly analogous to the chlorination results due to the rapid conversion of $\mathrm{Cl}^{-}$to free chlorine by ozone oxidation in these high $\mathrm{Cl}^{-}$waters. Specifically, for the high $\mathrm{Br}^{-}$waters (NSW and HBSW) with 15 min contact, the dominant HNM was again DBN, followed by BCNM, TCNM, CNM and BNM (Table 4). For the LBSW, the ozone results tracked the chlorine results with TCNM at nearly an order of magnitude higher concentration than those of all the other species (Table 4). Additional experiments were performed on a different set of samples from these same marine basins using a longer contact time of $60 \mathrm{~min}$ at an oxidant dose of $3 \mathrm{mg} \mathrm{L}^{-1}$. The data showed very analogous results to the 15 min contact time experiments with DBNM being the dominant byproduct in the two high $\mathrm{Br}^{-}$waters (NSW and HBSW), and TCNM being dominant in the LBSW (Table 5). The concentrations of CNM, BNM and BCNM were all greater at the longer contact times for NSW and HBSW, while the concentrations of all HNMs were greater at the longer contact times for the LBSW.

\subsection{Unknown DBPs formation}

An important observation during the LLE-GC/MS detection of HNMs was the formation of several unidentified DBPs during chlorination and ozonation. These unidentified compounds were not detected in the water samples collected and shipped to our laboratory from the aquaria, but formed during further disinfection treatment with chlorine and ozone. For the NSW and HBSW (but not the LBSW), several unknown compounds were formed (as indicated by several significant GC-MS peaks in the chromatograms, e.g., at 9.76, 11.24, 11.33 and 11.56 min (Figs. 1 and 2)) after treatment with ozone and chlorine. The size of the unidentified peaks correlated with $\mathrm{Br}^{-}$concentrations with the largest unknown peaks in NSW and the smallest in LBSW. Both chlorine and ozone formed the same primary unknown DBPs, consistent with the trend for chlorine and ozone for the known DBPs discussed above.

Greater chlorine (and ozone (data not shown)) concentrations ( 3 versus $1 \mathrm{mg} \mathrm{L}^{-1}$ ) also increased the magnitude of these peaks as shown, for example, in total ion chromatograms (TICS) for NSW after treatment with 0,1 , and $3 \mathrm{mg} \mathrm{L}^{-1}$ free chlorine in Fig. 1. The mass spectra for the major unknown peaks are presented in Fig. 2. A search of the Agilent GC/MS spectra library did not result in any high quality matches for these compounds. It is hypothesized that these compounds were relatively unstable because they were not detected in the water samples received from any of the aquaria (including NSW and HBSW), indicating they might have decomposed or evaporated, or converted to different compounds within the $24-48 \mathrm{~h}$ shipment and storage time prior to analysis. Additional study is needed to identify these unknowns.

\section{Conclusions}

The highest $\mathrm{Br}^{-}$concentration was detected in filtered natural seawater (NSW at $64.0 \mathrm{mg} \mathrm{L}^{-1}$ ) followed by high bromide saltwater (HBSW at $26.9 \mathrm{mg} \mathrm{L}^{-1}$ ), and then low bromide saltwater (LBSW at $\left.1.9 \mathrm{mg} \mathrm{L}^{-1}\right)$. These differences in $\mathrm{Br}^{-}$concentrations were an important factor in speciation of inorganic species as well as formation of HAAs and HNMs. The highest HNM concentrations were in LBSW at up to $75 \mu \mathrm{g} \mathrm{L}^{-1}$, more than 25 times those reported in the drinking water. Generally, the predominant HAAs and HNMs were chlorinated species in the low $\mathrm{Br}^{-}$system and mixed bromo- and chloro-species in the higher natural and synthetic water systems.

It was observed that the water samples collected in a warmer month (May) had generally greater concentrations of DBPs than those collected in a cooler month (January) in the higher $\mathrm{Br}^{-}$ waters. It is hypothesized that this may result from the increased reaction rates or possibly from increased aquaria loadings.

Bromate concentration was extremely high in the water from LBSW basin reaching $3700 \mu \mathrm{g} \mathrm{L}^{-1}$ (as compared with a $10 \mu \mathrm{g} \mathrm{L}^{-1}$ drinking water MCL for bromate) due in large measure to the zero-discharge nature of the treatment system. There was no 
detectable bromate in the NSW system and an intermediate amount in the HBSW (which uses some wasting and dilution with fresh feed). $\mathrm{I}^{-}$concentration in the three parks ranged approximately from 30 to $100 \mu \mathrm{g} \mathrm{L}^{-1}$. Major species of iodo-compound observed was iodate.

These results show that moderate to high concentrations of DBPs in the marine aquaria are present including haloacetic acids, halonitromethanes, bromate, and other compounds (e.g., trihalomethanes (Shi and Adams, 2012)) not identified in this study.

\section{Acknowledgments}

The authors thank Alex Winters and Kristine Brown (Missouri S\&T) for their help with sample preparation, sample receiving, and conducting DPD tests.

\section{References}

Beech, J.A., Diaz, R., Ordaz, C., Palomeque, B., 1980. Nitrates, chlorates and trihalomethanes in swimming pool water. Am. J. Public Health 70, 79-82.

Chen, P.H., Richardson, S., Krasner, S.W., Majetich, G., Glish, G.L., 2002. Hydrogen abstraction and decomposition of bromopicrin and other trihalogenated disinfection byproducts by GC/MS. Environ. Sci. Technol. 36, 3362-3371.

Eichelsdörfer, D., Slovak, J., 1975. Irritant effect (conjunctivitis) of chlorine and chloramines in swimming pool water. Vom Wasser 45, 17-28.

Krasner, S.W., Pastor, S., Chinn, R., Sclimenti, M.J., Weinberg, H.S., Richardson, S.D., Thruston, A.D., Jr., 2001. In: Proceedings of the 2001 AWWA WQTC; AWWA: Denver, CO, 2001.

Krasner, S., Wienberg, H., Richardson, S., Pastor, S., Chinn, R., Sclimenti, M., Onstad, G., Thruston, A., 2006. Occurrence of a New Generation of Disinfection Byproducts. Environ. Sci. Technol. 40, 7175-7185.
Plewa, M.J., Wagner, E.D., Jazwierska, P., Richardson, S.D., Chen, P.H., McKague, A.B. 2004. Halonitromethane drinking water disinfection by-products: chemical characterization and mammalian cell cytotoxicity and genotoxicity. Environ. Sci. Technol. 38, 62-68.

Reed, R., Adams, C., 2003. In: Proceedings of the International Ozone Association Pan-American Group Conference, Raleigh-Durham, NC, USA (May 21, 2002).

Richardson, S.D., Thruston Jr., A., Caughran, T., Chen, P., Collette, T., Floyd, T., Schenckand, K., Lykins Jr., B., 1999. Identification of new drinking water disinfection byproducts formed in the presence of bromide. Environ. Sci Technol. 33, 3378-3383.

Richardson, S., Plewa, M., Wagner, E., Schoeny, R., Demarini, D., 2007. Occurrence genotoxicity, and carcinogenicity of regulated and emerging disinfection byproducts in drinking water: a review and roadmap for research. Mutation Research 636, 178-242.

Shi, H., Adams, C., 2012. Occurrence and Formation of trihalomethane in Marine Aquaria Studied Using Solid Phase Microextraction Gas Chromatography-Mass Spectrometry. Water Environment Research. 84, 202-208.

Shi, H., Adams, C., 2009. Rapid IC-ICP/MS method for simultaneous analysis of iodoacetic acids, bromoacetic acids, bromate, and other related halogenated compounds in water. Talanta 79, 523-527.

USEPA, National primary drinking water regulations 2006: Stage 2 Disinfectants and Disinfection byproducts rule, Fed. Reg. 71, pp. 387-493 (www.epa.gov, National Primary Drinking Water Standards).

USEPA Method 300.1 1997. Determination of Inorganic Anions in Drinking Water by Ion Chromatography.

USEPA Method 326 2002. Determination of Inorganic Oxyhalide Disinfection byproducts in Drinking Water Using Ion Chromatography Incorporating the Addition of a Suppressor Acidified Post Column Regent for Trace Bromate Analysis.

Weinberg, H.S., Krasner, S.W., Richardson, S.D., Thruston, A.D., Jr. 2002. The occurrence of Disinfection by-products (DBPs) of Health Concern in Drinking Water: Results of a Nationwide DBP Occurrence Study, EPA/600/R02/068, US Environmental Protection Agency, National Exposure Research Laboratory, Athen, GA, 2002. www.epa.gov/athens/publications/EPA_600_R02_068.pdf.

Zwiener, C., Richardson, S.D., Demarini, D., Grummt, T., Glauner, T., Frimmel, A. 2007. Drowning in disinfection byproducts? Assessing swimming pool water. Environ. Sci. Technol. 41, 636-672. 